\title{
Chemoradiotherapy-Associated Myelosuppression: A Retrospective Analysis of Risk Factors for Patients with Non-Small Cell Lung Cancer
}

\author{
Ufuk Mehmet Yllmaz ${ }^{1}$, Serhat Erol ${ }^{1}$, Burcu Yalçın¹, Ceyda Anar ${ }^{1}$, \\ Yasemin Özdoğan ${ }^{1}$ Ümit Gürlek², Hasan Yılmaz ${ }^{2}$
}

${ }^{1}$ Clinic of Pulmonary Disease, Dr. Suat Seren Chest Diseases and Surgery Training and Research Hospital, İzmir ${ }^{2}$ Clinic of Radiation Oncology, Dr. Suat Seren Chest Diseases and Surgery Training and Research Hospital, Izmir

\begin{abstract}
Objective: Concomitant chemoradiotherapy (CRT) is the standard treatment for patients with stage III non-small cell lung cancer (NSCLC). Myelosuppression can be a significant problem in concomitant CRT. The aim of this study was to assess the parameters obtained before concomitant CRT to define the risk factors for myelosuppression in patients with locally advanced NSCLC.

Methods: We retrospectively analyzed 81 patients with NSCLC who received concomitant platinum-based chemoradiotherapy between January 2008 and December 2012. Seventy-eight patients (96.2\%) received etoposide (50 mg/m², intravenously on days 1-5, 29-33) plus cisplatin (50 mg/ $\mathrm{m}^{2}$, on days $1,8,29$, and 36$)$, and 3 patients (3.8\%) received docetaxel $\left(20 \mathrm{mg} / \mathrm{m}^{2} / \mathrm{w}\right.$, on weeks $\left.1-8\right)$ plus cisplatin $\left(20 \mathrm{mg} / \mathrm{m}^{2} / \mathrm{w}\right.$, on weeks $\left.1-8\right)$ concurrently with thoracic radiotherapy to a total dose of 40-66.6 Gy. The risk factors were examined for their association with myelosupression (grade 3 or 4 leukopenia, neutropenia, thrombocytopenia, or anemia) by logistic regression analysis.

Results: Grade 3 or higher neutropenia, leukopenia, thrombocytopenia, or anemia occurred in $51.8 \%, 53 \%, 8.6 \%$, and $7.4 \%$ of the patients, respectively. Multivariate analysis revealed that the risk factors for neutropenia were performance status ( $\mathrm{p}=0.032$ ), white blood cell count ( $\mathrm{p}=0.023)$, and pretreatment creatinine level $(p=0.018)$. On multivariate analysis, white blood cell count (OR, 3.311; $p=0.027 ; 95 \%$ CI, $1.148-9.545)$ was found as significant risk factor for CRT-induced leukopenia

Conclusion: Patients with a poor pretreatment performance status, low white blood cell count, and high creatinine level are at a risk of myelosupression. These characteristics of the patients should be considered while making treatment decisions.
\end{abstract}

Keywords: Chemoradiotherapy, lung cancer, neutropenia, risk factors

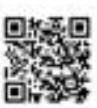

Received Date: 12.11.2014

Accepted Date: 19.01.2015

Available Online Date: 27.02.2015

Address for correspondence

Serhat Erol, Clinic of Pulmonary Disease, Dr. Suat Seren Chest Diseases and Surgery Training and

Research Hospital, İmir, Turkey

E-mail: drserol@yahoo.com (1) 9 This work is licensed under a Creative 4.0 International License.

DOI: $10.5152 /$ ejp.2015.87487

-Available online at www.eurasianjpulmonol.com

\section{INTRODUCTION}

Approximately one-third of patients with non-small cell lung cancer (NSCLC) have locally advanced disease at the time of diagnosis. A meta-analysis of randomized trials have shown that appropriately selected patients with locally advanced NSCLC have a survival advantage when treated with concomitant chemoradiotherapy (CRT), which is now a widely used type of treatment for such patients (1). The addition of induction or consolidation chemotherapy concomitant CRT results in increased toxicities but does not further improve survival compared with CRT alone in patients with stage III inoperable $\operatorname{NSCLC}(2,3)$.

In the trials including meta-analysis, the reported grade 3 to 4 hematological toxicity rates were highly variable across trials, from fewer than $20 \%$ to more than $90 \%$, as the type of chemotherapy and the timing of control blood counts were different among trials (1). Thus, patients who develop grade 3 or 4 myelosuppression often cause treatment interruptions and increase the risks of infection or bleeding. Therefore, myelosuppression worsens the patient quality of life (QoL) and can cause prolonged hospitalization. Unscheduled interruptions in radiotherapy have been associated with a reduced probability of local control of tumors in patients with lung cancer receiving potentially curative treatments (4). It would be crucial to identify the patients who are the highest risk of myelosuppression. Thus, high-risk patients could be monitored more closely for myelosuppression. 
In a previous study, Jiang et al. (5) examined the association between patient characteristics and CRT-induced myelosuppression in advanced NSCLC. They reported some risk factors for myelosuppression; however, $35.5 \%$ of their patients received induction chemotherapy before CRT (5). Therefore, the results of their trial do not properly explain the risk factors of myelosuppression in patients treated with concomitant CRT alone, which is now a widely used type of treatment.

To the best of our knowledge, there has been no study examining the risk factors for myelosuppression in patients with locally advanced NSCLC treated with concomitant CRT alone. The purpose of this study was to identify risk factors associated with grade 3-4 myelosuppression in these patients.

\section{METHODS}

\section{Patients}

A total of 81 patients with stage IIIA and B NSCLC, consecutively treated with concomitant chemoradiotherapy between January 2008 and December 2012, were identified in our departmental database. All patients comprised the study cohort.

Eligible patients had the following criteria: histological/cytological diagnosis of NSCLC, no prior radiotherapy (RT) or chemotherapy; ECOG performance status (PS) of 0 to 1 at baseline; unintended weight loss of $<10 \%$ in the 6 months; and adequate pretreatment bone marrow (absolute neutrophil count $\geq 1,500 / \mu \mathrm{L}$, platelets $\geq 100,000 / \mu \mathrm{L}$, and hemoglobin $\geq 10 \mathrm{~g} / \mathrm{dL}$ ), renal (serum creatinine $\leq 1.3 \mathrm{mg} / \mathrm{dL}$ or calculated creatinine clearance $\geq 50 \mathrm{~mL} / \mathrm{min}$ ), and hepatic function. Patients were excluded if they had malignant effusions (pleural or pericardial) or significant cardiac disease (unstable angina, myocardial infarction in the previous year, congestive heart failure, uncontrolled hypertension, or ventricular arrhythmias requiring medication). The protocol was approved by institutional ethics review boards, and all patients provided written informed consent before the treatment.

This study was approved by the Ethics Committee of Dr. Suat Seren Chest Disease and Surgery Training and Research Hospital. Informed consent was obtained from all patients for procedures and the use of medical records.

\section{Treatment Schedules}

Eligible patients were intravenously (IV) treated with $50 \mathrm{mg} / \mathrm{m}^{2}$ cisplatin on days $1,8,29$, and 36 plus IV $50 \mathrm{mg} / \mathrm{m}^{2}$ etoposide on days $1-5$ and $29-33$ or with weekly IV $20 \mathrm{mg} / \mathrm{m}^{2}$ docetaxel on weeks $1-8$. Thoracic $\mathrm{RT}$ was administered as 1.8-2.0 Gy daily treatments for 5 days each week, starting within 1 hour of the first day of chemotherapy. The total doses of RT were 40-66.6 Gy.

\section{Clinical Parameters Before Treatment}

Data were collected on all patients for age, sex, amount of weight loss in six months before treatment, body mass index (BMI), body surface area (BSA), ECOG performance status (PS), clinical TNM staging, and radiation dose. Disease stages were classified as per the TNM classification of the International Union against Cancer $7^{\text {th }}$ edition $(6,7)$.

\section{Biological Parameters Before Treatment}

Blood tests were performed before starting the treatment, and the following parameters were measured: white blood cell count (WBC), hemoglobin $(\mathrm{Hb})$, platelet count $(\mathrm{Plt})$, serum creatinine $(\mathrm{Cr})$, lactate dehydrogenase (LDH), albumin (Alb), and calculated creatinine clearance $(\mathrm{CrCl})$. Creatinine clearance was determined as 140 - patient age $\times$ weight in kilograms $/ 72 \times$ serum creatinine $\times(0.85$ for female patients).

\section{Toxicity}

The endpoint of this survey was the occurrence of grade 3-4 anemia, thrombocytopenia, leukopenia, and neutropenia. Myelosuppression was assessed on a weekly basis during CRT and graded 0-4 according to the National Cancer Institute Common Toxicity Criteria (ver 3.0). Grade 3-4 myelosuppressions were determined by analyzing the collected hematological data.

\section{Statistical Analysis}

The clinical and biological parameters were examined for their association with myelosuppression (grade 3 and 4 anemia, thrombocytopenia, leucopenia, and neutropenia) by univariate analysis with chisquare or Fisher's exact test. The moderately significant factors at the $<0.25$ level were considered for inclusion in a multivariate analysis. For multivariate analysis, logistic regression was used to identify independent risk factors for CRT-induced myelosuppression in patients with lung cancer. For each factor, the odds ratio and $95 \%$ confidence interval were calculated and $p<0.05$ was considered to be significant. Statistical analysis was performed using SPSS (Version 16.0. SPSS Inc, Chicago, IL, USA).

\section{RESULTS}

\section{Patient Characteristics}

From January 2008 to December 2012, 81 patients with a clinically staged IIIA and B of NSCLC were enrolled in this study. Seventy-eight patients were treated with cisplatin plus etoposide. Baseline histopathological characteristics and demographical features of the patients are listed in Table 1. The median age at diagnosis was 57 years (range, 40-72), wherein males constituted a majority of the group ( $n=78,92.6 \%$ ). The most predominant histological type was squamous cell carcinoma $(53 ; 65.4 \%)$, followed by adenocarcinoma (14; $17.3 \%)$ and NSCLC, unidentified for subtypes (14; 17.3\%). Further, 52 patients (64.1\%) had a good PS (ECOG 0), and the other patients had PS 1.

In all included patients, grade 3-4 myelosuppressions were observed as follows: neutropenia in 42 (51.8\%), leukopenia in 43 (53\%), thrombocytopenia in 7 (8.6\%), and anemia in 6 (7.4\%).

\section{Risk Factors for Neutropenia}

On univariate analysis, CRT-induced neutropenia was associated with age, PS, BSA, WBC, $\mathrm{Cr}$, and $\mathrm{Crcl}(\mathrm{p}<0.25)$. On multivariate analysis, PS [odds ratio (OR), 3.196; $\mathrm{p}=0.032 ; 95 \%$ confidence interval $(\mathrm{Cl}), 1.104-$ 9.524], WBC (OR, 3.250; $\mathrm{p}=0.023 ; 95 \% \mathrm{Cl}, 1.173-9.009)$ and $\mathrm{Cr}(\mathrm{OR}$, $3.325 ; \mathrm{p}=0.018 ; 95 \% \mathrm{Cl}, 1.228-8.999$ ) were shown to be independent significant risk factors for neutropenia ( $p<0.05$; Table 2 ). 


\begin{tabular}{|c|c|c|c|c|c|}
\hline & n & $\%$ & Mean \pm SD & Min & Max \\
\hline Age (years) & & & $55.6 \pm 7.8$ & 40 & 72 \\
\hline$<60$ & 53 & 65.5 & & & \\
\hline$\geq 60$ & 28 & 34.5 & & & \\
\hline \multicolumn{6}{|l|}{ Sex } \\
\hline Male & 78 & 96.2 & & & \\
\hline Female & 3 & 3.8 & & & \\
\hline \multicolumn{6}{|l|}{ ECOG } \\
\hline 0 & 52 & 64.2 & & & \\
\hline 1 & 29 & 35.8 & & & \\
\hline Body mass index $\left(\mathrm{kg} / \mathrm{m}^{2}\right)$ & & & $24.5 \pm 4.3$ & 14.8 & 38.5 \\
\hline$\leq 18.5$ & 5 & 6.2 & & & \\
\hline$>18.5$ & 76 & 93.8 & & & \\
\hline Body surface area $\left(\mathrm{m}^{2}\right)$ & & & $1.8 \pm 0.1$ & 1.5 & 2.2 \\
\hline$<2$ & 68 & 83.9 & & & \\
\hline$\geq 2$ & 13 & 16.1 & & & \\
\hline \multicolumn{6}{|l|}{ Weight loss } \\
\hline Yes & 24 & 29.6 & & & \\
\hline No & 57 & 70.4 & & & \\
\hline \multicolumn{6}{|l|}{ TNM stage } \\
\hline IIIA & 39 & 48.2 & & & \\
\hline IIIB & 42 & 51.8 & & & \\
\hline Radiotherapy dose & & & $60.8 \pm 6.1$ & 40 & 66 \\
\hline$>60 \mathrm{~Gy}$ & 68 & 83.9 & & & \\
\hline$\leq 60 \mathrm{~Gy}$ & 13 & 16.1 & & & \\
\hline White blood cell count $\left(\times 10^{3} / \mu \mathrm{L}\right)$ & & & $10.9 \pm 12.8$ & 5.9 & 14.9 \\
\hline$<10000$ & 50 & 61.7 & & & \\
\hline$\geq 10000$ & 31 & 38.3 & & & \\
\hline Hemoglobin (g/dL) & & & $13.1 \pm 1.4$ & 9.1 & 15.9 \\
\hline$>11$ & 75 & 92.5 & & & \\
\hline$\leq 11$ & 6 & 7.5 & & & \\
\hline Platelet $\left(\times 10^{4} / \mu \mathrm{L}\right)$ & & & $35.9 \pm 13$ & 11.8 & 89.4 \\
\hline$<300000$ & 26 & 32 & & & \\
\hline$\geq 300000$ & 55 & 68 & & & \\
\hline $\mathrm{LDH}(\mathrm{IU} / \mathrm{L})$ & & & $199.0 \pm 78$ & 93 & 740 \\
\hline$<250$ & 70 & 86.4 & & & \\
\hline$\geq 250$ & 11 & 13.6 & & & \\
\hline Albumine $(\mathrm{g} / \mathrm{dL})$ & & & $3.9 \pm 0.4$ & 2.7 & 4.6 \\
\hline$<3$ & 4 & 5 & & & \\
\hline$\geq 3$ & 77 & 95 & & & \\
\hline Creatinine (mg/dL) & & & $0.9 \pm 0.1$ & 0.5 & 1.3 \\
\hline$<1$ & 43 & 53 & & & \\
\hline$\geq 1$ & 38 & 47 & & & \\
\hline Creatinine clearance $(\mathrm{mL} / \mathrm{min})$ & & & $90.0 \pm 16.9$ & 47.3 & 145 \\
\hline$<70$ & 72 & 88.8 & & & \\
\hline$\geq 70$ & 9 & 11.2 & & & \\
\hline
\end{tabular}

\section{Risk Factors for Leukopenia}

On univariate analysis, age, PS, BMI, BSA, WBC, Hb, and Ccrl were shown to be risk factors for leukopenia $(p<0.25)$. On multivariate analysis, WBC (OR, 3,311; $\mathrm{p}=0.027 ; 95 \% \mathrm{Cl}, 1.148-9.545)$ was found as significant risk factor for CRT-induced leukopenia ( $p<0.05$; Table 2).

\section{Risk Factors of Anemia and Thrombocytopenia}

On univariate analysis, BSA, stage, RT dose and WBC were proved to be risk factors for anemia. CRT-induced thrombocytopenia was associated with age, PS, radiation dose, LDH, albumin, and $\mathrm{Ccrl}(\mathrm{p}<0.25)$. On multivariate analysis, no significant association was found between patient characteristics and anemia or thrombocytopenia ( $p>0.05$, Table 2).

\section{DISCUSSION}

The aim of the present study was to identify risk factors that may affect myelosuppression in patients with locally advanced NSCLC treated with concomitant CRT. Severe neutropenia induced by chemoradiotherapy is associated with the potential risk of toxic death because of infection and may interrupt in radiotherapy or chemotherapy. It would be useful to identify risk factors for severe neutropenia during chemoradiotherapy. This audit has provided some insight into the risk of neutropenic complications. From the multivariate analysis, PS, pretreatment WBC and creatinine level identified as significant risk factors that independently contributed for neutropenia; pretreatment WBC was identified for leukopenia.

The treatment of this patient population remains controversial because of the heterogeneity of the patients with locally advanced NSCLC. Surgery alone is not recommended as the standard therapy. Further, primary surgery has been shown to have poor outcomes in certain subgroups of patients with this disease. The most common treatment modalities are concomitant CRT or in some patients trimodality therapy, which involves CRT followed by surgery. The aims of the concomitant chemoradiotherapy are the improvement of local control and eradication of distant metastasis, while avoiding excessive toxicities. The delivery of full-dose chemotherapy may be required for reducing distant failure; however, this may be problematic because of toxicities, such as esophagitis, pneumonitis, or myelosuppression. Chemotherapy and radiotherapy cause different types of bone marrow injury. Chemotherapy causes injures all of the bone marrow. In contrast, bone marrow injury occurs only within the irradiated volume during radiotherapy (8).

Table 2. Multivariate analysis of risk factors for myelosuppression

\begin{tabular}{|c|c|c|c|c|}
\hline Myelosuppression & Risk factors & OR & $95 \% \mathrm{Cl}$ & $p$ \\
\hline \multirow[t]{3}{*}{ Neutropenia } & ECOG 0 (vs 1) & 3.196 & $1.104-9.524$ & $0.03^{*}$ \\
\hline & $W B C \geq 10000$ (vs $<10000)$ & 3.250 & $1.173-9.009$ & $0.02^{*}$ \\
\hline & $\mathrm{Cr}(\mathrm{mg} / \mathrm{dL})<1(\mathrm{vs} \geq 1)$ & 3.325 & $1.228-8.999$ & $0.01^{*}$ \\
\hline Leukopenia & WBC $\geq 10000$ (vs < 10000) & 3.311 & $1.148-9.545$ & $0.02^{*}$ \\
\hline $\begin{array}{l}\mathrm{p}<0.05 \\
\mathrm{Cl}: \text { Confidenc } \\
\text { Group } \mathrm{OR}: \mathrm{O}\end{array}$ & te blood cell & 0 & & \\
\hline
\end{tabular}


Cisplatin plus etoposide is most frequently used in combination with concomitant radiotherapy in patients with lung cancer. Grade 3 and 4 hematological toxicities associated with concomitant CRT with cisplatin plus etoposide were as follows in the study by Hanna et al. (2). In patients receiving CRT alone, 32\% experienced grade 3-4 neutropenia, 5.9\% had grade 3-4 anemia, and $10.8 \%$ experienced thrombocytopenia. In other trial, grade 3-4 anemia was observed in $28 \%$ of patients. Grade 4 neutropenia occurred in $32 \%$ of patients (9). In our study, grades 3-4 neutropenia and leukopenia were most frequently detected, and thrombocytopenia and anemia occurred in 42 (51.8\%), $43(53.0 \%), 7(8.6 \%)$, and $6(7.4 \%)$ patients, respectively. Grade 3-4 neutropenia was more frequent in the present study than in the studies by Hanna et al. (2) and Albain et al. (9).

The performance status is a general measure of the patient functional status. Moreover, there is a correlation between a poor PS and tolerability of treatment for patients with lung cancer. Patients with PS 2 were at a higher risk of severe toxicity than those with PS $0 / 1(5,10)$. However, in trials comprising patients with lung cancer treated with concurrent CRT, patient eligibility criteria comprises an ECOG performance status of 0 or 1 at baseline. It was a widely postulated opinion that patients with PS 0 or 1 were at the same risk of severe toxicity. From our investigation, we found that patients with PS 1 had a 3.196-times higher risk of neutropenia than those with PS 0 $(p=0.03)$.

Creatinine clearance has been a commonly used tool for determining the renal function of cancer patients. Reduced creatinine clearance is associated with toxicities. Further, creatinine clearance is known to be a predictor of hematological toxicity in non-platinum chemotherapy regimen in a study by Lheureux (11). Our study did not reveal any association between neutropenia and creatinine clearance. However, our study revealed that baseline creatinine level was associated with severe neutropenia after CRT for lung cancer. We found that patients with baseline creatinine level $\geq 1 \mathrm{mg} / \mathrm{dL}$ had a 3.325-times higher risk of neutropenia than those with $<1 \mathrm{mg} / \mathrm{dL}(\mathrm{p}=0.01)$ but for not leukopenia. Furthermore, Jiang $\mathrm{N}$ et al. (5) found that creatinine $>0.9$ $\mathrm{mg} / \mathrm{dL}$ was associated with a 3.478-fold greater incidence of grade 3-4 leukopenia. Previous studies have also shown that patients with a pretreatment creatinine level $>1.0 \mathrm{mg} / \mathrm{dL}$ had a higher risk of leukopenia $(12,13)$.

It has also been reported that pretreatment WBC counts are predictive of severe neutropenia in patients with early-stage breast cancer $(14,15)$. In our study, patients with lower pretreatment WBC are more likely to experience grade 3-4 neutropenia and leukopenia with higher risk of 3,250 and 3,311, respectively. Low WBC may probably indicate bone marrow insufficiency.

The patients in the highest risk group for severe neutropenia defined as pretreatment creatinine level $\geq 1 \mathrm{mg} / \mathrm{dL}$, pretreatment WBC counts $<10.000$, and ECOG PS of 1 in our cohort, none of our variables were found to be independently associated with thrombocytopenia and anemia. The most important risk factors for treatment interruption with thrombocytopenia based on multivariate analysis were concurrent chemoradiotherapy in analysis by Mac Manus et al. (16). Anemia is a not an uncommon complication in patients receiving chemotherapy and radiotherapy. A decrease in $\mathrm{Hb}$ count can lead to several symptoms, such as fatigue, asthenia, and the deterioration of life quality. The incidence of grade 3-4 anemia and thrombocytopenia ( $7.4 \%$ and $9.6 \%$, respectively) were low rate in our study. Therefore, we could not detect any risk factor for anemia and thrombocytopenia.

This study has the following disadvantages: 1) A single center with a relatively small number of patients and 2) The incidence of grade 3-4 anemia and thrombocytopenia were low rate. They also had the following disadvantages: 1) Almost all analyzed patients were treated with cisplatin and etoposide regimen (96.2\%) and 2) All patients were treated with concomitant CRT alone. As a result, the patients constituted the homogenous group.

Although the present study was a small-scale review of actual clinical practice, this information on grade 3-4 neutropenia and leukopenia is considered to markedly contribute to the safe and effective use of concurrent chemoradiotherapy for the treatment of locally advanced NSCLC.

\section{CONCLUSION}

Patients with a poor pre-treatment performance status, low white blood cell count, and high creatinine level are at a risk of myelosuppression. These patient characteristics should be considered while making treatment decisions.

Ethics Committee Approval: Ethics committee approval was received for this study from the ethics committee of Dr. Suat Seren Chest Disease and Surgery Training and Research Hospital.

Informed Consent: Informed consent was obtained from all patients for procedures and the use of medical records.

Peer-review: Externally peer-reviewed.

Author contributions: Concept - U.Y., S.E., B.Y., Y.Ö., C.A., Ü.G., H.Y.; Design U.Y., S.E., B.Y., C.A., Y.Ö., Ü.G., H.Y.; Supervision - U.Y., S.E., B.Y., Y.Ö., C.A., Ü.G., H.Y.; Materials - U.Y., Y.Ö., C.A.; Data Collection and/or Processing - U.Y., H.Y., Ü.G., C.A.; Analysis and/or Interpretation - U.Y., H.Y., Ü.G., S.E., C.A., Y.Ö., B.Y.; Literature Search - U.Y., S.E., C.A., Y.Ö.; Writing - U.Y., C.A., Y.Ö., S.E., B.Y., H.Y., Ü.G.; Critical Reviews - U.Y., S.E., C.A., Y.Ö., B.Y., H.Y., Ü.G.

Conflict of Interest: No conflict of interest was declared by the authors.

Financial Disclosure: The authors declared that this study has received no financial support.

\section{REFERENCES}

1. Auperin A, Le Pechoux C, Rolland E, Curran WJ, Furuse K, Fournel P, et al. Meta-analysis of concomitant versus sequential radiochemotherapy in locally advanced non-small-cell lung cancer. J Clin Oncol 2010; 28: 218190. [CrossRef]

2. Hanna N, Neubauer M, Yiannoutsos C, McGarry R, Arseneau J, Ansari R, et al. Phase III study of cisplatin, etoposide, and concurrent chest radiation with or without consolidation docetaxel in patients with inoperable stage III non-small-cell lung cancer: the Hoosier Oncology Group and U.S. Oncology. J Clin Oncol 2008; 26: 5755-60. [CrossRef] 
3. Vokes EE, Herndon JE 2nd, Kelley MJ, Cicchetti MG, Ramnath N, Neill H, et al. Induction chemotherapy followed by chemoradiotherapy compared with chemoradiotherapy alone for regionally advanced unresectable stage III non-small-cell lung cancer: Cancer and Leukemia Group B. J Clin Oncol 2007; 25: 1698-704. [CrossRef]

4. Cox JD, Pajak TF, Asbell S, Russell AH, Pederson J, Byhardt RW, et al. Interruptions of high-dose radiation therapy decrease long-term survival of favorable patients with unresectable non-small cell carcinoma of the lung: analysis of 1244 cases from 3 radiation therapy oncology group (RTOG) trials. Int Radiat Oncol Biol Phys 1993; 27: 493-8. [CrossRef]

5. Jiang N, Chen XC, Zhao Y. Analysis of the risk factors for myelosuppression after concurrent chemoradiotherapy for patients with advanced nonsmall cell lung cancer. Support Care Cancer 2013; 21: 785-91. [CrossRef]

6. Goldstraw P (ed). Staging Manual in Thoracic Oncology. Denver: IASLC; 2009.

7. International Union against Cancer. Sobin LH, Gospodrowicz MK, Wittekind CH (ed), TNM Classification of Malignant Tumours, 7th Ed. New York: Wiley-Liss; 2009.

8. Chemotherapy in non-small cell lung cancer: a meta-analysis using updated data on individual patients from 52 randomised clinical trials. Non-small Cell Lung Cancer Collaborative Group. Br Med J 1995; 311: 899-909. [CrossRef]

9. Albain KS, Crowley JJ, Turrisi AT 3rd, Gandara DR, Farrar WB, Clark Jl, et al. Concurrent cisplatin, etoposide, and chest radiotherapy in pathologic stage IIIB non-small-cell lung cancer: a Southwest Oncology Group phase II study, SWOG 9019. J Clin Oncol 2002; 20: 3454-60. [CrossRef]
10. Armstrong TS, Cao Y, Scheurer ME, Vera-Bolanos E, Manning R, Okcu MF, et al. Risk analysis of severe myelotoxicity with temozolomide: the effects of clinical and genetic factors. Neuro Oncol 2009; 11: 825-32. [CrossRef]

11. Lheureux S, Clarisse B, Launay-Vacher V, Gunzer K, Delcambre-Lair C, Bouhier-Leporrier $\mathrm{K}$, et al. Evaluation of current practice: management of chemotherapy-related toxicities. Anticancer Drugs 2011; 22: 919-25. [CrossRef]

12. Matsui K, Masuda N, Uchida Y, Fukuoka M, Negoro S, Yana T, et al. Determinants of myelosuppression in the treatment of non-small cell lung cancer with cisplatin-containing chemotherapy. Jpn J Cancer Res 1996; 87: 781-6. [CrossRef]

13. Armstrong TS, Cao Y, Scheurer ME, Vera-Bolanos E, Manning R, Okcu MF, et al. Risk analysis of severe myelotoxicity with temozolomide: the effects of clinical and genetic factors. Neuro Oncol 2009; 11: 825-32. [CrossRef]

14. Morrison VA, Caggiano V, Fridman M, Dale DC, Crawford J, Delagado DJ, et al. A model to predict chemotherapy-related severe or febrile neutropenia in cycle one among breast cancer and lymphoma patients. J Clin Oncol (Meeting Abstracts) 2004; 22: 8068.

15. Jenkins $P$, Freeman $S$. Pretreatment haematological laboratory values predict for excessive myelosuppression in patients receiving adjuvant FEC chemotherapy for breast cancer. Ann Oncol 2009; 20: 34-40. [CrossRef]

16. Mac Manus M, Lamborn K, Khan W, Varghese A, Graef L, Knox S. Radiotherapy-associated neutropenia and thrombocytopenia: analysis of risk factors and development of a predictive model. Blood 1997; 89: 2303-10. 